\title{
THE ERYTHEMATOGENOUS ACTION OF ULTRAVIOLET LIGHT \\ ON HUMAN SKIN. I. SOME MEASUREMENTS OF THE SPECTRAL RESPONSE WITH CONTINUOUS AND INTERMITTENT LIGHT
}

\author{
BY PAUL B. ROTTIER \\ (From the Laboratory for Histology and Microscopic Anatomy of the University, \\ Utrecht, Holland)
}

(Submitted for publication January 8, 1953; accepted April 1, 1953)

\section{INTRODUCTION}

A short time after irradiation of the skin with ultraviolet light, an erythema develops. The effective spectral range has been measured by Hausser and Vahle $(1,2)$ and has been verified by Luckiesh, Holladay, and Taylor (3) and Coblentz and Stair (4). These investigators are agreed that there are two wave length regions of high activity with maxima near $297 \mathrm{~m} \mu$ and $250 \mathrm{~m} \mu$, and one of low activity with a minimum near $280 \mathrm{~m} \mu$ (see Figure 1). They differ, however, in their reports of the relative activities of the two regions in producing a maximal erythema response. Hausser and Vahle (1) found an almost negligible activity at $250 \mathrm{~m} \mu$ as compared with that at 297 $\mathrm{m} \mu$. Later (2), however, he noted greater activity at the shorter wave length (see curves 1 and 2 in Figure 1). Luckiesh, Holladay, and Taylor (3) found an almost equal activity for both regions (Figure 1, curve 3 ) whereas the findings of Coblentz and Stair (4) (Figure 1, curve 4), finally, were similar to those of Hausser (2) in 1928.

According to Mitchell (5), the reason for this discrepancy should be sought in the experimental difficulties that arise when working with wave lengths shorter than $280 \mathrm{~m} \mu$. The great variability in the sensitivity of the skin to ultraviolet light mentioned in the literature (6) might also hold for the relative sensitivity at different wave lengths and in this way provide an explanation for the discrepancy found by various investigators.

In an effort to localize the erythematogenous processes in the several layers of the skin, we attacked the problem again by irradiating human skin through a quartz spectrograph in order to study the responses for the whole spectrum as did Hausser and Oehmcke (7) who used the skin of bananas. We chose this method because it provided an easy means of comparing the erythem- atous response of several subjects exposed to different wave lengths.

\section{METHOD}

\section{The spectrograph}

For the irradiation of the skin a small $f / 4.5$ quartz spectrograph was constructed consisting of a $60^{\circ}$ quartz prism as described by Cornu and two quartz lenses with $\pm 14 \mathrm{~cm}$. focal length.

The source of light was a high pressure mercury lamp (HP $80 \mathrm{~W}$ ). To get the highest intensities possible the lamp was placed at the entrance slit. Between the lamp and the collimator lens we placed a series of seven diaphragms. The first of these diaphragms $(8 \times 0.5$ $\mathrm{mm}$.) was situated at a distance of $5 \mathrm{~mm}$. from the lamp, the others successively farther away and of greater width to ensure a complete filling of the collimator lens. In a like manner five diaphragms were placed between the second lens and the place where the spectrum is formed in order to avoid as much stray radiation as possible.

At the back of the spectrograph, where the spectrum is formed, a quartz object-glass was placed against which the skin could be held.

The casement of the lamp was water cooled and could be moved back and forth for the purpose of adjusting the sharpness of the spectral lines. This sharpness was judged prior to each experiment by means of a fluorescent plate held against the quartz object-glass. The lamp operated both on direct and on alternating current. Although calculated for 80 Watts the lamp could easily be used with 2 Amps. $-125 \mathrm{~V}$. to get shorter irradiation times. In order to avoid overheating, the lamp was cooled by a jet of nitrogen from a bomb. Used in this way the lamp could operate at 250 Watts for over 20 hours.

The dimensions of the whole spectrum formed by the spectrograph were $33 \times 8 \mathrm{~mm}$. The surface area covered by the active part $(313-248 \mathrm{~m} \mu)$ was $13 \mathrm{~mm}$. long by $8 \mathrm{~mm}$. wide. The smallness of this area has two advantages, first, as several irradiations can be performed on a relatively small skin area there is little risk of local differences in the sensitivity of the skin, second, even heavy doses of ultraviolet light will have no serious systemic effect. 


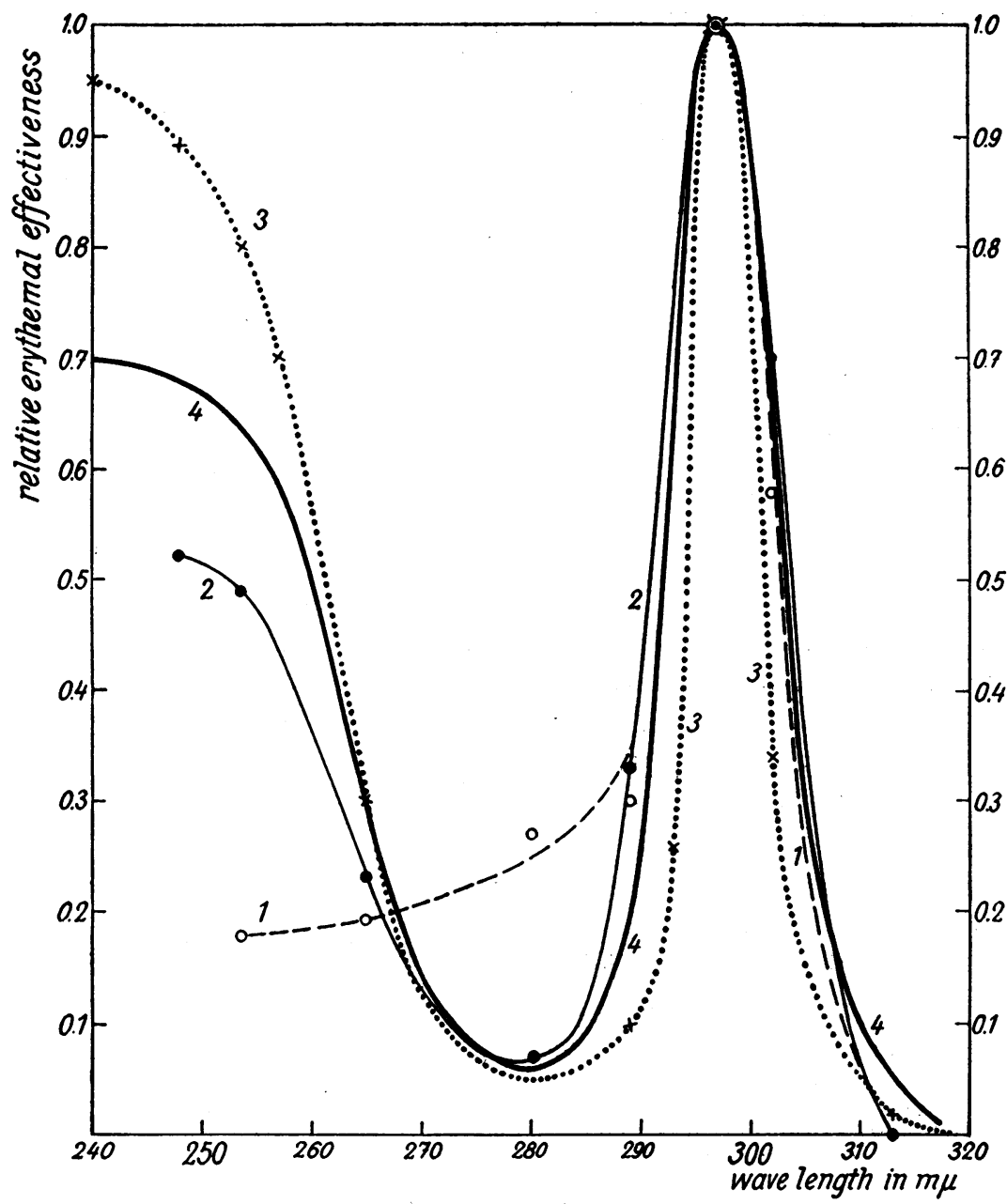

Fig. 1. Erythema Action Spectrum as Determined by Otheir Investigators

Curve 1 : Hausser and Vahle, 1921. Curve 2: Hausser, 1928. Curve 3 : Luckiesh, Holladay, and Taylor, 1930. Curve 4: Coblentz and Stair, 1934.

\section{Determination of the active spectral lines}

Irradiation of the skin of the forearm, which is lightly pressed against the quartz object-glass at the back of the spectrograph, for an appropriate time (one to three minutes when the lamp is used with 2 Amps.) leads to the development of an erythema, after six to ten hours,

TABLE I

Linear distances of the spectral lines from the $546 \mathrm{m \mu}$ line

\begin{tabular}{cccc}
\hline $\begin{array}{c}\text { Line } \\
m \mu\end{array}$ & $\begin{array}{c}\text { Distance } \\
m m .\end{array}$ & $\begin{array}{c}\text { Line } \\
m \mu\end{array}$ & $\begin{array}{c}\text { Distance } \\
m m .\end{array}$ \\
\hline 436 & 3.0 & 289 & 18.8 \\
405 & 5.0 & 280 & 20.5 \\
366 & 8.2 & 265 & 23.8 \\
334 & 11.9 & 257 & 25.7 \\
313 & 14.9 & 253 & 27.3 \\
302 & 16.6 & 248 & 28.3 \\
297 & 17.5 & 240 & 30.8 \\
\hline
\end{tabular}

at the sites of the active spectral lines. The determination of the wave lengths by which the erythema is caused is done in the following way. The site of the green line of the mercury spectrum with a wave length of 546 $\mathrm{m} \mu$ and the short wave length end of the spectrum are marked with two ink lines on the quartz object glass just before placing the skin against it. After the irradiation, the localization of the spectrum is marked on the arm by reprints of the ink lines. The irradiated skin is then outlined with ink. When the erythema has appeared as a red line $(8 \times 2 \mathrm{~mm}$.) on the skin, the distance of this red line from the site of the $546 \mathrm{~m} \mu$ line-already indicated in ink on the skin-is measured. The linear distances of all spectral lines from this $546 \mathrm{m \mu}$ line have been measured on a photograph of the whole spectrum. Table I gives these distances. With these values the wave length of the erythematogenous line is found.

The spectral lines by themselves are only $0.5 \mathrm{~mm}$. wide but an erythema caused by them is initially $1 \mathrm{~mm}$. wide, 
later broadening to approximately $2 \mathrm{~mm}$. At longer wave lengths than $302 \mathrm{~m} \mu$ an erythema has never been observed. On normal skin the lines 302 and $297 \mathrm{~m} \mu$ provoke only one red band with a width of $2 \mathrm{~mm}$. This is a conspicuous band and as such is used for the most part as a wave length reference for the other red lines provoked by the shorter wave lengths. Of these the most constantly observed is that provoked by the line $257 \mathrm{~m} \mu$ (this is not strictly a line but a broad band as is seen in Figure 2). The $257 \mathrm{~m} \mu$ erythema also occupies a space of approximately $2 \mathrm{~mm}$. Besides this erythema, often those provoked by the $265 \mathrm{~m} \mu$ and the $248 \mathrm{~m} \mu$ lines can be observed when they start to develop. Later on these three lines fuse into one broad red patch $5 \mathrm{~mm}$. wide, situated at a distance of $5 \mathrm{~mm}$. from the $302-$ $297 \mathrm{~m} \mu$ erythema. The $253 \mathrm{~m} \mu$ erythema has not been observed separately.

Curiously enough, in two cases a distinct erythema was observed at the site of the $280 \mathrm{~m} \mu$ line (between the $302-297 \mathrm{~m} \mu$ red patch and that of $265-248 \mathrm{~m} \mu$ ), where the erythematous activity should be very low. In these two cases exceptionally high doses had not been used, so that an abnormal sensitivity of the skin must have existed. This phenomenon has not been studied further.

\section{Evaluation of the spectral response}

We have restricted our attention to a more or less quantitative evaluation of the two principal erythematous
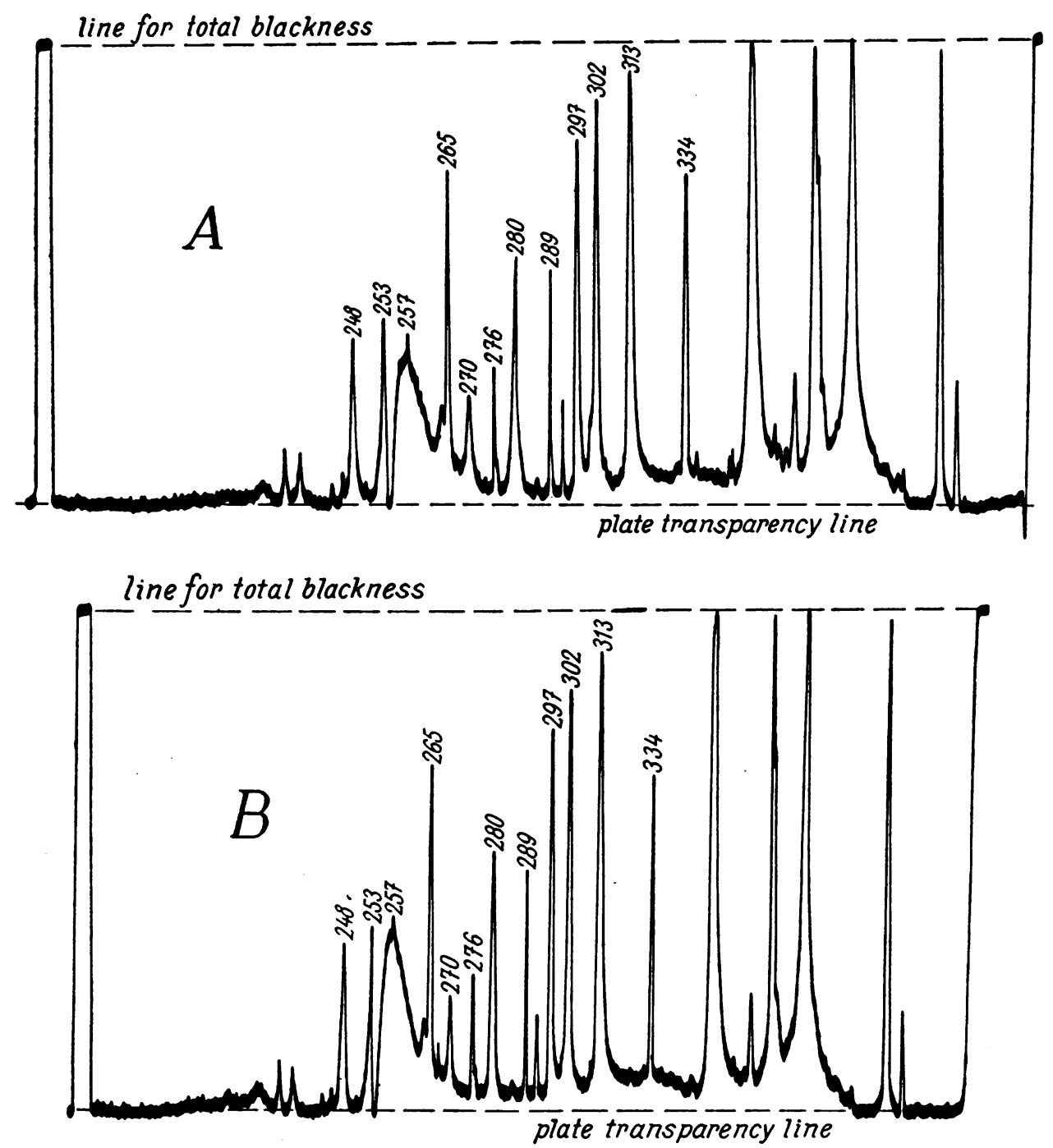

Fig. 2. Microphotometer Registrations of the Spectrum of the Mercury Lamp (2 Amps)

A : alternating, B : direct current. Only the region near $257 \mathrm{~m} \mu$ is significantly different in intensity. (As both curves are photographic magnifications of the original registrations to obtain equal height for equal intensities, the wave length scale has become different.) 
responses at the wave lengths of maximal activity, vis. at $302-297 \mathrm{~m} \mu$ and at $265-248 \mathrm{~m} \mu$.

There are two different ways to judge the effect of ultraviolet irradiation of the skin: (1) by measuring the degree of redness for a given irradiation dose or, (2) by measuring the irradiation dose which provokes a justperceptible erythema.

The first of these methods is the less applicable to our purpose. An erythema develops slowly and reaches a maximum 10 to 14 hours after the irradiation. It is not easy to find an irradiation time which produces a maximum redness just matching a given color standard. There is no linear correlation between irradiation dose and degree of redness. Therefore interpolation between two color standards of different redness is not accurate. Moreover erythematous responses to different wave lengths do not change in proportion to identical increases in irradiation doses. The longer the wave length, the greater is the increase in redness with heavier doses (Hausser [2]).

For these reasons we chose the second method of comparing the two responses under discussion, viz. by measuring the irradiation dose which provokes a just-perceptible erythema. This method is easily performed as will be clear from the description in the following section.

Both methods have been employed for the determination of the relative effects of irradiation with light of different wave lengths. The first method was used by Hausser (Figure 1, curve 2), the second by Coblentz and Stair (Figure 1, curve 4), without any great difference in result. This agreement may have been due to chance.

Erythema is the result of the widening of the subepidermal capillaries, which vary greatly in number per unit area of skin. The entire area covered by these capillaries is a relatively small fraction of the total area. The color of the skin is determined by a mixture of light reflected from the external surface of the skin and light thrown back after refraction in the epidermal cells and the subepidermal tissue (8). Part of the refracted light passes through the capillaries and the deeper vessels, thus giving a reddish component to the color of the skin. With erythema only a small fraction of the light is changed by the dilated capillaries. The rest of the light that determines the color of the skin remains unaffected, unless fluid passes through the capillary walls, possibly changing the light diffusing properties of the surrounding tissues. Especially with more intense erythemata this may confuse the issue.

Accordingly, the only correlation between irradiation dose and degree of redness of the skin is an increase in the redness with increasing doses, but this increase in redness is difficult to calculate. Hausser estimated the degree of redness of the 297 and $250 \mathrm{m \mu}$ erythemata by comparing them with pieces of paper colored with different quantities of a red dye. He found that the $297 \mathrm{~m} \mu$ erythema matched a paper containing twice as much dye as the paper that matched the $250 \mathrm{~m} \mu$ erythema (which had been produced by the same energy as the $297 \mathrm{~m} \mu$ erythema). His conclusion that irradiation at $297 \mathrm{~m} \mu$ induced capillary dilation two times greater than that at
$250 \mathrm{~m} \mu$, or that a double stimulus strength had been in operation, seems inadmissable. On the other hand, the spectral response determined by measuring the minimum erythema dose (MED) will be quite different for different skins for the reasons stated above. Thus, a priori, it is not to be expected that both methods will give the same results when used on different skins.

Therefore, we are of the opinion that the different action spectra, found by different investigators, as shown in Figure 1, are not due to experimental difficulties encountered with ultraviolet light of short wave lengths (Mitchell [5]), but might be physiologically significant.

\section{Determination of the minimal erythema dose}

As has been discussed in the preceding section we determined the irradiation times necessary to provoke a just perceptible erythema with the whole spectrum of the spectrograph. The procedure adopted was as follows. On the skin of the forearm three or four doses were given

TABLE II

Minimal erythema dose (MED) for the two wave length

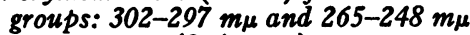

(2 Amps.,)

\begin{tabular}{|c|c|c|c|c|c|c|c|c|}
\hline \multirow{3}{*}{$\begin{array}{l}\text { Time } \\
\text { elapsed } \\
\text { since the } \\
\text { irradia- } \\
\text { tion }\end{array}$} & \multicolumn{8}{|c|}{ Irradiation time in seconds } \\
\hline & \multicolumn{2}{|c|}{45} & \multicolumn{2}{|c|}{60} & \multicolumn{2}{|c|}{75} & \multicolumn{2}{|c|}{90} \\
\hline & 300 & 250 & 300 & 250 & 300 & 250 & 300 & 250 \\
\hline $\begin{array}{c}\text { hours } \\
5 \\
6 \\
8 \\
9 \\
10 \frac{1}{4} \\
11 \\
12 \frac{1}{4} \\
13 \frac{1}{4} \\
14 \frac{3}{4} \\
23\end{array}$ & $\begin{array}{l}- \\
- \\
\pm \\
\pm \\
\pm \\
\pm \\
\pm \\
\pm \\
\pm \\
-\end{array}$ & $\begin{array}{l}\overline{-} \\
- \\
\bar{x} \\
\pm \\
\pm \\
\pm \\
+ \\
\pm \\
-\end{array}$ & $\begin{array}{c}- \\
- \\
\overline{ \pm} \\
\pm \\
+ \\
+ \\
++ \\
++ \\
++ \\
-\end{array}$ & $\begin{array}{c}- \\
\overline{-} \\
\pm \\
+ \\
++ \\
++ \\
++ \\
++ \\
-\end{array}$ & $\begin{array}{l}- \\
\bar{t} \\
+ \\
+ \\
++ \\
++ \\
++ \\
++ \\
++ \\
++\end{array}$ & $\begin{array}{c}\overline{-} \\
\bar{x} \\
\pm \\
+ \\
++ \\
++ \\
++ \\
++ \\
\pm\end{array}$ & $\begin{array}{c}\bar{x} \\
+ \\
++ \\
++ \\
++ \\
++ \\
++ \\
++ \\
++ \\
++\end{array}$ & $\begin{array}{c}- \\
\overline{ \pm} \\
\pm \\
\pm+ \\
+t \\
+t \\
+t \\
+t \\
+t \\
+\end{array}$ \\
\hline
\end{tabular}

by increasing the duration of the subsequent irradiations. From about the fifth hour the irradiated spots were observed at hourly intervals and developing erythemata noted with the following signs:

$$
\begin{aligned}
& \text { - no erythema } \\
& \pm \text { reaction uncertain } \\
& + \text { just perceptible } \\
& ++ \text { distinct erythema }
\end{aligned}
$$

From the complete list of observations the minimum erythema dose is easily computed as is shown in Table II.

In this way careful observation every hour makes it possible to determine the MED with an accuracy of approximately 20 per cent. After some experience two or three irradiation doses should suffice to obtain this accuracy. 
TABLE III

Minimal erythema doses (MED) with irradiation* using direct or alternating current

\begin{tabular}{|c|c|c|c|c|c|c|}
\hline \multicolumn{3}{|c|}{ Person } & \multirow{2}{*}{$\begin{array}{l}\text { Skin } \\
\text { area } \\
\text { used }\end{array}$} & \multirow{2}{*}{$\begin{array}{l}\text { Wave } \\
\text { length } \\
\text { group }\end{array}$} & \multirow{2}{*}{$\begin{array}{c}\text { MED } \\
\text { (alter- } \\
\text { nating } \\
\text { current) }\end{array}$} & \multirow{2}{*}{$\underset{\substack{\text { MED } \\
\text { current) }}}{\text { current) }}$} \\
\hline $\begin{array}{l}\text { No. } \\
\text { and } \\
\text { sex }\end{array}$ & Age & Skin tan & & & & \\
\hline $10^{7}$ & \pm 60 & none & fore arm & $\begin{array}{c}m \mu \\
300 \\
250\end{array}$ & $\begin{array}{r}\text { sec. } \\
70 \\
70\end{array}$ & $\begin{array}{r}\text { sec. } \\
95 \\
70\end{array}$ \\
\hline $2 \sigma^{7}$ & \pm 60 & moderate & fore arm & $\begin{array}{l}300 \\
250\end{array}$ & $\begin{array}{r}90 \\
300\end{array}$ & $\begin{array}{r}90 \\
150\end{array}$ \\
\hline 3 o' & \pm 25 & none & fore arm & $\begin{array}{l}300 \\
250\end{array}$ & $\begin{array}{l}50 \\
50\end{array}$ & $\begin{array}{l}65 \\
50\end{array}$ \\
\hline 49 & 5 & strong & shoulder & $\begin{array}{l}300 \\
250\end{array}$ & $\begin{array}{l}180 \\
240\end{array}$ & $\begin{array}{l}300 \\
420\end{array}$ \\
\hline $5 \%$ & 12 & none & shoulder & $\begin{array}{l}300 \\
250\end{array}$ & $\begin{array}{l}30 \\
60\end{array}$ & $\begin{array}{l}30 \\
60\end{array}$ \\
\hline 69 & 11 & none & shoulder & $\begin{array}{l}300 \\
250\end{array}$ & $\begin{array}{r}90 \\
150\end{array}$ & $\begin{array}{l}120 \\
120\end{array}$ \\
\hline 79 & 7 & none & shoulder & $\begin{array}{l}300 \\
250\end{array}$ & $\begin{array}{l}50 \\
90\end{array}$ & $\begin{array}{l}\mathbf{5 0} \\
\mathbf{5 0}\end{array}$ \\
\hline
\end{tabular}

* The source of irradiation was a lamp operating on both direct and alternating current of equal strength (2 Amps., 250 Watts).

\section{Mechanical influence on the sensitivity of skin}

Experiments that might show the presence of a photosensitive substance on the skin were performed by washing the skin before irradiation with cotton soaked in alcohol or ether, and with brush and soap. These manipulations caused a distinct increase in the degree of erythema as compared with the degree of erythema in the untreated skin. Even rubbing the skin with a finger for some minutes until a distinct redness had appeared showed this effect. These experiments demonstrate how varying degrees of vasolability may influence the apparent sensitivity of the skin. During experiments for determining sensitivity, care must be taken, therefore, not to irritate the skin mechanically.

\section{RESULTS AND COMMENT}

Table III shows the result of MED determinations for seven persons, with the lamp burning on direct as well as on alternating current, both of equal strength (2 Amps.). ${ }^{1}$

1 The voltage depended somewhat on the lamp used; values from 124 to $132 \mathrm{~V}$ have been found. Thus different lamps could consume from 228 to 264 Watts. As each experiment was completed with the same lamp, these differences of less than 10 per cent from the mean of 246 Watts have not been taken into account.
As will be seen from the figures of Table III we found, as did all other authors, very different values for the MED for different persons. This statement also holds for the $302-297 \mathrm{~m} \mu$ group as well as for the other and there is only a very slight correlation between both groups.

Stress should be laid upon the fact that these MED values are by no means definitive or characteristic of these persons, as other values may be found at other times.

\section{Reversal of the MED of the two wave length groups with direct current}

When we used the lamp with alternating current-as we did in our first experiments-the MED of the $300 \mathrm{~m} \mu$ group was always found to be shorter in seconds irradiation time than that of the $250 \mathrm{~m} \mu$ group. The $300 \mathrm{~m} \mu$ erythema usually appeared first and was the strongest for a given irradiation time, as is illustrated by subjects 2,4 , 5, 6, and 7 (Table III). But later, when direct current was used, a reversal in the time of appearance and in the intensity of both erythemata was sometimes noted. Subjects 1 and 3 (Table III) showed this reversal of the MED with direct current. With these two individuals the use of direct current required a longer irradiation time to provoke the $300 \mathrm{~m} \mu$ MED. This reversal in the appearance of the two erythemata after irradiation with direct current had nothing to do with a difference in sensitivity to ultraviolet light. From subjects 2, 4, 5, 6, and 7 (Table III), who did not show the reversal, subject 5 was more sensitive than subjects 1 and 3 , who did show the reversal, subject 7 had almost the same sensitivity, subjects 2,4 , and 6 were less sensitive.

\section{Comparison of the activity of each wave length group for direct and alternating current}

When a certain MED had been found for the $300 \mathrm{~m} \mu$ group with alternating current it follows from the figures of Table III that the MED in seconds irradiation time for direct current could be longer (subjects $1,3,4$, and 6 ) or equal (subjects 2 and 5 ) but not shorter. Thus, one may conclude that the $300 \mathrm{~m} \mu$ group is more active with intermittent light than with continuous light.

No such rule has been found for the $250 \mathrm{~m} \mu$ group. The MED for subjects 2, 6, and 7 was 
shorter for direct current than for alternating current, equal in subjects 1,3 , and 5 , and longer in subject 4. Thus no final conclusion can be drawn as to the influence of intermittency of irradiated light.

From these observations it seems to follow that there is an unmistakable influence exerted by the kind of current used, which, in turn, determines the type of light produced, intermittent or continuous. Before drawing this conclusion, however, it is necessary to measure the intensities radiated by the lamp with both types of current. It is well known that the relative intensities of the spectral lines depend on the conditions under which a mercury lamp works. Thus it could be possible that our lamp emitted different intensities in the two active wave length groups when used with direct or with alternating current. In the following paragraphs we have described the experiments that were done to clarify this point.

\section{The relative intensities of the spectral lines}

In order to measure the intensities of the wave lengths emitted by the HP $80 \mathrm{~W}$, the spectrum was calibrated photographically in the following way.

The lamp was placed 3 meters in front of the spectrograph. At the original site of the lamp an entrance slit $2 \times 0.1 \mathrm{~mm}$. was fitted. Close to the entrance slit a shutter device was placed which permitted a range of exposure time from 0.01 to 9.00 seconds with an accuracy of better than 0.001 second. This shutter device consisted of an aluminum disk with an adjustable sector opening and an automatic shutter rotated by a small synchronous motor. The photographic plate $(6 \times 9 \mathrm{~cm}$.) could be moved up and down in the usual manner, so that there was ample space on each plate for 14 photographs of spectra-each $2 \mathrm{~mm}$. high. Seven spectraeach time using a double exposure time-were taken of the HP $80 \mathrm{~W}$ alternating with seven spectra of an absolutely calibrated Krefft standard lamp (9), situated at the same place as the HP $80 \mathrm{~W}$. The densities of the spectra were registered photographically with a microphotometer (type C of Moll, N. V. Kipp \& Zonen, Delft). An example is given in Figure 2. From these densities the intensities of the spectral lines were derived graphically in the usual manner. The intensity of the continuum was also measured and taken into account.

This calibration was done for the HP $80 \mathrm{~W}$ burning on direct current and on alternating current (50 cycles per second). First, a possible intermittency effect on the photographic plate was studied by taking seven spectra of the Krefft lamp burning with 2.0 Amps. direct current (for which this lamp had been calibrated) and then by taking seven spectra with double exposure times through a rotating sector disk giving 50 interruptions per second, each of 0.01 second. On Gevaert Replica $23^{\circ} \mathrm{S}$ an intermittency effect could not be found with certainty and thus has not been taken into account.

Table IV shows the total intensities for several spectral lines of the HP $80 \mathrm{~W}$ with both direct and alternating current. As is seen in Table IV the intensities of the lamp burning with alternating current are a little lower (mean, 4 per cent) than with direct current. Although the accuracy of the photographic method is of the order of \pm 5 to 10 per cent and thus does not permit a final conclusion, this difference of 4 per cent might be significant because the lower temperature the lamp will attain with alternating current falls to zero 100 times a second.

For our purpose the conclusion may be drawn that the intensities of the lamp for both types of current are the same. This holds also for each spectral line, especially those that can provoke an erythema (boldface in Table IV) if they have sufficient strength. Only the line with wave length $257 \mathrm{~m} \mu$ is an exception since it provokes a significantly more intense response with direct current than with alternating current. This is a relatively weak line superposed upon a strong continuum of the $253.7 \mathrm{~m} \mu$ line which itself shows

TABLE IV

Total intensities (line plus continuum) of the high pressure mercury lamp-HP $80 \mathrm{~W}$ (Philips)*

\begin{tabular}{cccc}
\hline \multirow{4}{*}{$\begin{array}{c}\text { Wave } \\
\text { length }\end{array}$} & \multicolumn{2}{c}{ Total intensity } & \\
\cline { 2 - 4 } & Direct & Alternating & Difference \\
\hline$m \mu$ & $m W /$ sterad & $m W /$ sterad & $\%$ \\
578 & 896 & 905 & -1 \\
546 & 1025 & 954 & +7 \\
436 & 755 & 705 & +7 \\
408 & 76 & 72 & +5 \\
405 & 386 & 366 & +5 \\
366 & 945 & 957 & +1 \\
334 & 85 & 80 & +6 \\
313 & 552 & 528 & +4 \\
& & 237 & +1 \\
302 & 159 & 154 & +3 \\
297 & 68 & 60 & 0 \\
289 & 90 & 84 & +7 \\
280 & 176 & 180 & +2 \\
265 & 85 & 72 & +15 \\
257 & 72 & 68 & +6 \\
253 & 69 & 64 & +7 \\
248 & & & \\
& & & +1 \\
\hline
\end{tabular}

* This lamp burned with 2.0 Amps. direct and alternating current. The lines with strong erythematous activity are printed in boldface. 
TABLE V

Minimal erythema dose calculated on basis of radiation intensity and time

\begin{tabular}{|c|c|c|c|c|c|c|}
\hline \multirow{2}{*}{ Person } & \multirow{2}{*}{$\begin{array}{l}\text { Spec- } \\
\text { tral } \\
\text { line }\end{array}$} & \multicolumn{2}{|c|}{$\begin{array}{c}\text { Minimal erythema } \\
\text { dose } \\
\text { mW/sterad } X \\
\text { seconds }\end{array}$} & \multirow{2}{*}{$\begin{array}{l}\text { Alter- } \\
\text { nating } \\
\text { current / } \\
\text { direct } \\
\text { current }\end{array}$} & \multicolumn{2}{|c|}{ Sensitivity } \\
\hline & & $\begin{array}{l}\text { Alter- } \\
\text { nating } \\
\text { current }\end{array}$ & $\begin{array}{c}\text { Direct } \\
\text { current }\end{array}$ & & $\begin{array}{c}\text { Alter- } \\
\text { nating } \\
\text { current }\end{array}$ & $\begin{array}{l}\text { Direct } \\
\text { current }\end{array}$ \\
\hline 1 & $\begin{array}{l}m \mu \\
297 \\
257\end{array}$ & $\begin{array}{r}1080 \\
504\end{array}$ & $\begin{array}{r}1500 \\
594\end{array}$ & $\begin{array}{l}0.72 \\
0.85\end{array}$ & $\begin{array}{l}\% \\
1.14 \\
1.96\end{array}$ & $\begin{array}{c}\% \\
1.13 \\
1.91\end{array}$ \\
\hline 2 & $\begin{array}{l}297 \\
257\end{array}$ & $\begin{array}{l}1380 \\
2160\end{array}$ & $\begin{array}{l}1430 \\
1280\end{array}$ & $\begin{array}{l}097 \\
1.69\end{array}$ & $\begin{array}{l}0.89 \\
0.46\end{array}$ & $\begin{array}{l}1.19 \\
0.88\end{array}$ \\
\hline 3 & $\begin{array}{l}297 \\
257\end{array}$ & $\begin{array}{l}770 \\
360\end{array}$ & $\begin{array}{r}1020 \\
425\end{array}$ & $\begin{array}{l}0.76 \\
0.85\end{array}$ & $\begin{array}{l}1.60 \\
2.74\end{array}$ & $\begin{array}{l}1.66 \\
2.66\end{array}$ \\
\hline 4 & $\begin{array}{l}297 \\
257\end{array}$ & $\begin{array}{l}2770 \\
1730\end{array}$ & $\begin{array}{l}4760 \\
3660\end{array}$ & $\begin{array}{l}0.85 \\
0.47\end{array}$ & $\begin{array}{l}0.44 \\
0.57\end{array}$ & $\begin{array}{l}0.36 \\
0.31\end{array}$ \\
\hline 5 & $\begin{array}{l}297 \\
257\end{array}$ & $\begin{array}{l}460 \\
432\end{array}$ & $\begin{array}{l}476 \\
510\end{array}$ & $\begin{array}{l}0.97 \\
0.85\end{array}$ & $\begin{array}{l}2.67 \\
2.29\end{array}$ & $\begin{array}{l}3.56 \\
2.22\end{array}$ \\
\hline 6 & $\begin{array}{l}297 \\
257\end{array}$ & $\begin{array}{l}1380 \\
1080\end{array}$ & $\begin{array}{l}1900 \\
1020\end{array}$ & $\begin{array}{l}0.73 \\
1.06\end{array}$ & $\begin{array}{l}0.89 \\
0.92\end{array}$ & $\begin{array}{l}0.89 \\
1.11\end{array}$ \\
\hline 7 & $\begin{array}{l}297 \\
257\end{array}$ & $\begin{array}{l}770 \\
647\end{array}$ & $\begin{array}{l}793 \\
425\end{array}$ & $\begin{array}{l}0.97 \\
1.52\end{array}$ & $\begin{array}{l}1.60 \\
1.53\end{array}$ & $\begin{array}{l}2.14 \\
2.66\end{array}$ \\
\hline
\end{tabular}

complete self-reversal in the HP $80 \mathrm{~W}$. As can be seen directly from the photographic registrations of the spectra of this lamp (Figure 2) the only real difference is just this continuum of line $253.7 \mathrm{~m} \mu$, which compared with the sharp edge at $253 \mathrm{~m} \mu$ is much more pronounced with direct than with alternating current.

Thus when the light of the lamp is irradiated through the spectrograph on the skin no difference is to be expected for the erythematous activity of the lines $302-297 \mathrm{~m} \mu$ with either current. But for the group near $257 \mathrm{~m} \mu$ a somewhat higher activity might be found with direct current.

\section{The relative energy of the spectral lines falling on the skin}

No attempt has been made to measure accurately the absolute intensities of the light falling on the skin. The great variability in sensitivity of human skin makes such measurements of little value (10). Coblentz and Stair (4) indicated a value of $50.10^{4}$ ergs per cm. ${ }^{2}$ at a wave length of $297 \mathrm{~m} \mu$ for untanned skin to provoke a just perceptible erythema. Hausser and Gauer (11) found $36.10^{4}$ ergs per $\mathrm{cm}^{2}$, Luckiesh, Holladay, and Taylor (3)
$43.10^{4}$ ergs per $\mathrm{cm}^{2}$, the Council on Physical Therapy proposed $18.10^{4}$ ergs per $\mathrm{cm}^{2}(10)$. A rough estimation yielded under our conditions values not far from that of Coblentz and Stair (4) but the light was falling onto the skin at a sharp angle. Thus with perpendicular irradiation a lower value would have been found.

For these reasons we have refrained from introducing an absolute value for the irradiation doses in our calculations. Instead we have preferred to multiply the irradiation times from Table III with the intensities from Table IV. This can be done in two ways.

The first method is to take both erythemata as a whole, then multiply the sum of the intensities for the wave lengths 302 and $297 \mathrm{~m} \mu$ and the sum of the intensities of the wave lengths $265,257,253$ and $248 \mathrm{~m} \mu$ with their respective irradiation times.

The second method is to use the wave lengths 297 and $257 \mathrm{~m} \mu$ as representative of both erythemata and, therefore, multiply only the intensities of these two wave lengths with the irradiation doses.

This second way has been chosen for the figures shown in Table $\mathrm{V}$ (third and fourth columns).

The values in Table $\mathrm{V}$ afford a more correct basis for judging the spectral response of the skin than those of Table III, as the former are then made independent of differences in the distribution of energy radiated by the lamp. This is especially true for the $257 \mathrm{~m} \mu$ wave length, where the lamp differs significantly when used with the two types of current, making judgment of the spectral response difficult for the values in Table III.

\section{Intermittency effect}

Table VI shows the mean values of the MED found in Table $\mathrm{V}$ for the two wave lengths considered and for both types of current used. Table VII represents the analogous values but calculated

TABLE VI

Mean values for minimal erythema dose (Table II)

\begin{tabular}{cccc}
\hline & \multicolumn{3}{c}{ Minimal erythema dose } \\
\cline { 2 - 4 } $\begin{array}{c}\text { Wave } \\
\text { length }\end{array}$ & $\begin{array}{c}\text { Inter- } \\
\text { mittent } \\
\text { light }\end{array}$ & $\begin{array}{c}\text { Contin- } \\
\text { uous } \\
\text { light }\end{array}$ & Difference \\
\hline$m \mu$ & sec. & sec. & $\%$ \\
297 & 1230 & 1697 & 38 \\
257 & 988 & 1131 & 14.5 \\
\hline
\end{tabular}


TABLE VII

Mean values for the MED, calculated with the sum of the intensities of all participating spectral lines

\begin{tabular}{cccc}
\hline \hline Wave length & $\begin{array}{c}\text { Intermittent } \\
\text { light }\end{array}$ & $\begin{array}{c}\text { Continuous } \\
\text { light }\end{array}$ & Difference \\
\hline $302-297 \mathrm{~m} \mu$ & 3134 & 4280 & $37 \%$ \\
$265-248 \mathrm{~m} \mu$ & 5261 & 5281 & $4 \%$ \\
\hline
\end{tabular}

by following the first way as is indicated in the preceding paragraph. Thus for the values in Table VII, the sum of the intensities of the $302-297$ $\mathrm{m} \mu$ lines and the sum of the intensities of the lines 265, 257, 253 and $248 \mathrm{~m} \mu$ were used.

From the figures of Table VI and VII, it is clear that no significant difference exists between the average MED for the $250 \mathrm{~m} \mu$ erythema with intermittent or with continuous light.

But the difference in the MED for the $300 \mathrm{~m} \mu$ group is significantly higher with continuous than with intermittent light. This difference is 37 to 38 per cent, which sharply exceeds the error of \pm 20 per cent in the determination of the individual MED. The accuracy in the determination of the mean MED will certainly be lower than 20 per cent, as is shown by the differences in the MED for the $250 \mathrm{~m} \mu$ erythema in Tables VI and VII.

Therefore, even if the considerations mentioned earlier do not permit us to draw a definite conclusion, the values of Tables VI and VII establish undeniably the influence of intermittent light in provoking the $300 \mathrm{~m} \mu$ erythema: continuous light requires greater energy and is, therefore, less active for this wave length group than intermittent light.

This effect is absent in the $250 \mathrm{~m} \mu$ group. Therefore the erythematogenous processes of both wave length groups must be different.

\section{Independence of erythematous responses to both wave length groups}

The fifth column of Table $\mathrm{V}$ shows a comparison of the MED values for intermittent and continuous light for each person and for both wave length groups. A figure lower than 1 indicates that a smaller amount of energy is needed to provoke the just-perceptible erythema using intermittent light than that needed with continuous light. For the $297 \mathrm{~m} \mu$ erythema all the figures are lower than 1 , in accordance with the conclusion drawn in the preceding paragraph. For the $250 \mathrm{~m} \mu$ erythema four figures are lower and three higher than 1 , thus confirming the absence of a distinct intermittency effect.

In general, the values of the fifth column (Table $\mathrm{V}$ ) are rather variable for different persons. This variability supports the conclusion drawn above that the processes leading finally to an erythema must be independent of each other for both wave length groups.

\section{Sensitivity of the skin for both wave length groups}

The last two columns in Table V show the sensitivities of the seven persons studied. These sensitivities have been calculated by dividing the mean values of the MED given in Table VI by those from columns 2 and 3 in Table V. A figure higher than 1 indicates a higher sensitivity than the mean

TABLE VIII

Sensitivity limits found for the seven persons from Table $V$

\begin{tabular}{ccc}
\hline $\begin{array}{c}\text { Wave length } \\
\text { group }\end{array}$ & $\begin{array}{c}\text { Intermittent } \\
\text { light }\end{array}$ & $\begin{array}{c}\text { Continuous } \\
\text { light }\end{array}$ \\
\hline & $\%$ & $\%$ \\
$300 \mathrm{~m} \mu$ & $0.44-2.67$ & $0.36-3.56$ \\
$250 \mathrm{~m} \mu$ & $0.46-2.74$ & $0.31-2.66$ \\
both groups & $0.44-2.74$ & $0.31-3.56$ \\
\hline
\end{tabular}

of these seven persons, a figure lower than 1 the reverse. In Table VIII the sensitivity limits found have been collected.

The sensitivity limits are of the order of $1 / 3-3$ times the mean. Our experience over a period of years with a total of some 25 persons for whom the MED has been determined with only intermittent light or for only one wave length group, has given us the impression that the figures in Table VIII may be considered to be the limits of normal sensitivity. A distinct abnormal sensitivity was determined at one time for a person who showed the $297 \mathrm{~m} \mu$ erythema in approximately $1 / 50$ of the normal time.

Of course statistical compilation of much more material than is given here will be necessary to settle correctly the problem of normal sensitivity for the different wave lengths that can provoke an erythema. It is clear that such a determination will make it possible to ascertain pathological devi- 
ations and will offer new possibilities for their better diagnosis.

\section{SUM MARY}

A simple method has been described to determine the erythematous response of skin to monochromatic radiation.

The result of measurements for the two main erythemata, viz. those provoked by the wave lengths 297 and $257 \mathrm{~m} \mu$, indicates the minimum irradiation doses needed to cause these erythemata to be mutually independent.

An undeniable effect of the intermittency of the light used for the irradiation has, moreover, been found for the $297 \mathrm{~m} \mu$ erythema alone.

The conclusion is therefore drawn that the processes leading to both erythemata must be different.

The variability in sensitivity of human skin has been found to be as great for irradiations with $250 \mathrm{~m} \mu$ as for those with $297 \mathrm{~m} \mu$.

\section{ACKNOWLEDGMENT}

I wish to thank Dr. H. Berkelbach van der Sprenkel for his permission to build the spectrograph and for his help with this work.

Also, I wish to thank Dr. J. J. Zoon, Head of the Dermatological Clinic, and his assistants for placing at my disposal several people for measurements.

\section{REFERENCES}

1. Hausser, K. W., and Vahle, W., Die Abhängigkeit des Lichterythems und der Pigmentbildung von der Schwingungszahl (Wellenlänge) der erreyenden Strahlung. Strahlentherapie, 1922, 13, 41.

2. Hausser, K. W., Einfluss der Wellenlänge in der Strahlenbiologie. Strahlentherapie, 1928, 28, 25.

3. Luckiesh, M., Holladay, L. L., and Taylor, A. H., Reaction of untanned human skin to ultraviolet radiation. J. Optic. Soc. America, 1930, 20, 423.

4. Coblentz, W. W., and Stair, R., Data on the spectral erythemic reaction of the untanned human skin to ultraviolet radiation. Bur. Stand. J. Res., 1934, 12, 13.

5. Mitchell, J. S., The origin of the erythema curve and the pharmacological action of ultra-violet radiation. Proc. Roy. Soc., London, s.B., 1939, 126, 241.

6. Ellinger, F., The Biologic Fundamentals of Radiation Therapy. Elsevier Publishing Co., New York, 1941.

7. Hausser, K. W., and Oehmcke, H. v., Lichtbräunung an Fruchtschalen. Strahlentherapie, 1933, 48, 223.

8. Edwards, E. A., and Duntley, S. Q., The pigments and color of living human skin. Am. J. Anat., 1939, 65,1 .

9. van Stekelenburg, L. H. M., Rapport No. 5. T. N. O: Afd. Gezondheidstechniek, Den Haag, 1951.

10. Blum, H. F., Radiation: Non-ionizing; Photophysiology and photopathology. Medical Physics, Glasser, O., Ed., Vol. II, The Year Book Publ., Inc., Chicago, 1950.

11. Hausser, K. W., and Gauer, O., Die absolute Empfindlichkert der Lichterythembildung. Strahlentherapie, 1933, 48, 230. 